\title{
ESTUDOS ANATÔMICOS EM RHAMNACEAE. CONSIDERAÇÕES TAXONÔMICAS, ECOLÓGICAS E EVOLUTIVAS ${ }^{1}$
}

\author{
SIDINEI RODRIGUES DOS SANTOS² JOSÉ NEWTON CARDOSO MARCHIORI ${ }^{3}$
}

\section{RESUMO}

Este trabalho tem por objetivo o estudo do lenho de cinco Ramnáceas nativas no Rio Grande do Sul, com vistas a identificar caracteres anatômicos de valor taxonômico, ecológico e evolutivo: Colletia paradoxa (Sprengel) Escalante, Discaria americana Gillies et Hooker, Gouania ulmifolia Hooker et Arnott, Rhamnus sphaerosperma Swartz e Scutia buxifolia Reissek. Das características em comum, destacam-se: poros não exclusivamente solitários; placas de perfuração simples; pontoações intervasculares alternas; parênquima paratraqueal escasso e em séries não estratificadas; raios heterogêneos tipo II, não estratificados e não exclusivamente unisseriados; além de fibras não septadas, com pontoações simples na parede. Para a separação anatômica das espécies, mostraram-se importantes: o volume ocupado pelos diferentes tecidos na madeira; o arranjo e forma dos poros; a presença de dimorfismo e de espessamentos espiralados em vasos; o tamanho de pontoações intervasculares; a presença de traqueídeos vasculares; o tipo e altura das séries de parênquima axial; a composição, largura e altura de raios; a espessura da parede de fibras; além da presença de cristais e de células perfuradas. Sob o ponto de vista anatômico, foram também reconhecidas características xeromórficas e evoluídas no lenho. A freqüência e diâmetro de poros, bem como o comprimento de elementos vasculares, estão aparentemente relacionados com o hábito de crescimento. É fornecida uma chave para a separação das mesmas.

Palavras-chave: Rhamnaceae, Anatomia da Madeira, Anatomia Ecológica, Xilema, Taxonomia da Madeira.

\begin{abstract}
[Anatomical studies on Rhamnaceae. Taxonomic, ecological and evolutionary aspects].

This work aims to investigate the wood anatomy of five Rhamnaceae species from Rio Grande do Sul state (Brasil), with regard to taxonomic, ecological and evolutionary aspects: Colletia paradoxa (Sprengel) Escalante, Discaria americana Gillies et Hooker, Gouania ulmifolia Hooker et Arnott, Rhamnus sphaerosperma Swartz e Scutia buxifolia Reissek. The five species showed the following common features: non-exclusively solitary pores; simple perforation plates; alternate intervessel pits; non-stratified and scarce paratracheal parenchyma; heterogeneous type II rays, non-stratified and non-exclusively unisseriate rays; and non-septate fibres, with simple pits in the walls. The five species may be distinguished by the following features: the fraction of tissues in the wood; the arrangement and shape of pores; the vessel dimorphism; the presence of spiral thickenings in vessels; the size of intervessel pits; the presence of vascular tracheids; the type and height of axial parenchyma strands; the composition, height and wide of rays; the presence of crystals and perforated ray cells; and the thickness of wall fibers. Xeromorphic and developed anatomical features were also recognized in the wood. Frequency and pore diameter, as well as the length of vascular elements, showed apparently related to species growth habit. A key is supplied to distinguish the five studied species.

Key words: Rhamnaceae, Wood Anatomy, Ecological Wood Anatomy, Xylem, Wood Taxonomy.
\end{abstract}

Recebido para publicação em 12-6-2008 e aceito para publicação em 17-10-2008.

2 Biólogo, bolsista do CNPq - Brasil, doutorando do Programa de Pós-Graduação em Engenharia Florestal, Departamento de Ciências Florestais, Universidade Federal de Santa Maria, CEP 97105-900, Santa Maria, RS, Brasil. sthurt.bio@gmail.com

3 Engenheiro Florestal, Dr., Professor Titular do Departamento de Ciências Florestais, Universidade Federal de Santa Maria, Santa Maria, RS, Brasil. Bolsista de Produtividade em Pesquisa, CNPq - Brasil. balduinia@mail.ufsm.br 


\section{INTRODUÇÃO}

Pouco expressiva, a família Rhamnaceae compreende 8 gêneros e 9 espécies de hábito muito variável no Rio Grande do Sul, incluindo desde árvores e arbustos, com freqüência xerófilos, até trepadeiras lenhosas. Cabe destacar o caráter relictual das espécies nativas no Estado, posto que todos os gêneros contam com apenas um representante, à exceção de Colletia. Apesar da diversidade morfológica e de evidentes problemas de delimitação e definição, as Rhamnaceae constituem um grupo monofilético (Schirarend, 1991; Richardson et al., 2000).

Os questionamentos taxonômicos em Rhamnaceae apontam para a necessidade de estudos multidisciplinares, com vistas ao esclarecimento das relações internas na família. Segundo Richardson et al. (2000), uma classificação baseada em dados moleculares, com o suporte de caracteres provindos de outras áreas, sobretudo da anatomia, morfologia e química, mostrase especialmente recomendável neste caso.

Pesquisas em anatomia da madeira prestam relevante contribuição à taxonomia vegetal há mais de um século, tendo comprovado especial utilidade no caso de gêneros e grupos taxonômicos superiores (Radford et al., 1975). Nestes níveis, a variabilidade estrutural costuma ser maior, embora nem sempre suficiente para a separação. A semelhança estrutural na subtribo Baccharinae, por exemplo, torna mais fácil o reconhecimento do grupo taxonômico como um todo, do que seus gêneros integrantes (Marchiori \& Oliveira-Deble, 2007). Em nível de espécie, a estrutura geralmente resulta homogênea, servindo apenas ocasionalmente para a identificação.

Apesar de sua reconhecida importância, são ainda escassos os estudos anatômicos em Rhamaceae, salientando-se, neste sentido, os trabalhos de Record (1939), Metcalfe \& Chalk (1972) e Schirarend (1991). Com relação às espécies nativas no Rio Grande do Sul, deve-se a Marchiori (1983) a única referência bibliográfica disponível (Colletia paradoxa).
Com relação à família, cabe destacar, de início, a extraordinária diversidade de hábito das espécies nativas, bem como de sua morfologia, que exibe notável tendência ao xeromorfismo, fornecendo elementos particularmente interessantes à investigação da estrutura interna, sob enfoque ecofisiológico.

A influência de fatores ambientais na estrutura anatômica da madeira é investigada desde o final do século XIX, quando Vesque relacionou o diâmetro dos vasos à disponibilidade de água (Baas, 1982). Entre os pioneiros, Webber (1936) observou que plantas esclerófilas e de desertos tendem a apresentar anéis estreitos, poros numerosos e de pequeno diâmetro, além de elementos de vaso curtos. A correlação entre anatomia e ecofisiologia tem sido confirmada por vários estudos, principalmente a partir da década de 1960 (Carlquist, 1966; Carlquist, 1975; Baas et al., 1983; Carlquist \& Hoekman, 1985; Baas \& Schweingruber, 1987; Lindorf, 1994; León, 2005). No Brasil, de acordo com Marcati et al. (2001), o trabalho pioneiro em anatomia ecológica deve-se a Mina-Rodrigues (1986), que investigou órgãos vegetativos de Pera glabrata (Euphorbiaceae) em duas tipologias: Floresta Mesófila Semidecídua e Cerrado.

Correlações entre anatomia e hábito vegetal foram igualmente estabelecidas. Baas et al. (1983) verificaram que o comprimento dos elementos vasculares é menor em arbustos do que em árvores, diminuindo de vegetações mésicas para xéricas. Segundo Baas \& Schweingruber (1987), perfurações escalariformes, porosidade em anel e vasos exclusivamente solitários são mais comuns em árvores do que em arbustos; a ocorrência de diferentes classes de diâmetro de vasos, por sua vez, bem como a presença de traqueídeos vasculares, segue tendência inversa.

Carlquist \& Hoekman (1985) destacam a ocorrência de traqueídeos em espécies arbustivas. Lianas, de acordo com Carlquist (1991), possuem estrutura anatômica muito peculiar e com características afins, relacionadas ao hábito trepador, destacando-se a presença 
de variações cambiais, dimorfismo de vasos, elementos vasculares de grande diâmetro, abundância de parênquima axial e pequena proporção de fibras.

A anatomia da madeira contribui, ainda, para o esclarecimento das relações filogenéticas entre plantas. Radford (1974) salienta que as mudanças evolutivas refletem-se de maneira mais clara no xilema secundário do que em qualquer outro tecido vegetativo, justificando o importante papel da anatomia da madeira para a interpretação evolutiva de plantas vasculares. Tendências na evolução do xilema secundário são reconhecidas por inúmeros estudos, inclusive de fósseis, permitindo estabelecer a direção em que se verificam as modificações de determinado caráter (da condição primitiva à especialização), e se estas são reversíveis (Kribs, 1935; Barghoorn, 1941; Bailey, 1953; Metcalfe \& Chalk, 1972; Dickison, 1975; Herendeen et al, 1999).

\section{MATERIAL ESTUDADO}

As informações da estrutura anatômica apresentadas na Tabela 1, bem como os dados referidos no texto, foram colhidas de publicações dos próprios autores, referidas na bibliografia citada. A estrutura anatômica das cinco espécies foi analisada com vistas a reconhecer caracteres úteis à identificação e separação das mesmas. Os dados foram igualmente confrontados com referências da literatura, incluindo aspectos ecológicos e evolutivos, com o objetivo de estabelecer possíveis tendências na estrutura anatômica da família.

Discaria americana e Colletia paradoxa são arbustos lenhosos de aspecto nitidamente xeromórfico, com caules fotossintetizantes transformados em espinhos decussados e folhas muito reduzidas, prontamente caducas. Restritas, no Brasil, aos estados de Santa Catarina e Rio Grande do Sul, habitam preferencialmente solos rochosos, em ambientes úmidos e ensolarados, sobretudo na orla de capões e matas ciliares (Johnston \& Soares, 1972).
Trepadeira lenhosa, Gouania ulmifolia distingue-se facilmente pelos ramos cilíndricos e frutos esquizocárpicos trialados. Nativa em todo o sul do Brasil, a espécie habita principalmente solos úmidos, em matas primárias, capoeiras, beira de rios e estradas (Bastos, 1990).

Árvore pequena e sem espinhos, Rhamnus sphaerosperma possui folhas perenes, alternas e pubescentes. A presença de tricomas, aliás, é o único caráter xeromórfico evidente em sua morfologia externa. Heliófila e seletiva higrófila, a espécie é muito característica das matas com Araucária no sul do Brasil, habitando solos geralmente úmidos, arenosos com húmus ou pedregosos, preferencialmente na orla de capões e beira de estradas (Bastos, 1993). A sua presença, todavia, é também referida para as florestas alagáveis do sudeste brasileiro (Souza \& Lorenzi, 2005).

Árvore pequena, com tronco pouco desenvolvido e densamente ramificado, Scutia buxifolia distingue-se pelas folhas subopostas, pequenas e coriáceas, bem como pelos ramos jovens quadrangulares, providos de robustos espinhos na axila das folhas. Nativa em todo o sul do Brasil, a espécie ocorre preferencialmente em solos úmidos compactados ou paludosos, mas também em solos secos, tanto na orla ou interior de matas com Araucária, como em capões, matas ciliares ou, até mesmo, como árvores isoladas em pleno campo (Bastos, 1989).

\section{CONSIDERAÇÕES TAXONÔMICAS}

Observadas nas cinco espécies em estudo, são comuns ao grupo taxonômico: poros numerosos, não exclusivamente solitários; elementos vasculares curtos, dotados de apêndices; placas de perfuração simples; pontoações intervasculares alternas não ornamentadas; parênquima paratraqueal escasso, em séries não estratificadas; raios heterogêneos tipo II, não estratificados e não exclusivamente unisseriados; e fibras libriformes não septadas. $\mathrm{O}$ conjunto de características anatômicas acima relacionado está de acordo com referências de Record \& 
TABELA 1: Principais características anatômicas das cinco madeiras estudadas.

\begin{tabular}{|c|c|c|c|c|c|}
\hline Caráter anatômico & C. $p$. & D. $a$. & G. u. & R. $s$. & $S . b$. \\
\hline Poros em padrão dentrítico & $\mathrm{x}$ & $\mathrm{x}$ & & & \\
\hline Poros solitários e em múltiplos radiais/racemiformes & & & $\mathrm{x}$ & $\mathrm{x}$ & $\mathrm{x}$ \\
\hline Dimorfismo de vasos & & & $\mathrm{x}$ & & \\
\hline Elementos vasculares curtos $(<389 \mu \mathrm{m})$ & $\mathrm{x}$ & $\mathrm{x}$ & $\mathrm{x}$ & $\mathrm{x}$ & $\mathrm{x}$ \\
\hline Presença de espessamentos espiralados & $\mathrm{x}$ & $\mathrm{x}$ & $\mathrm{x}$ & $\mathrm{x}$ & \\
\hline Placas de perfuração simples & $\mathrm{x}$ & $\mathrm{x}$ & $\mathrm{x}$ & $\mathrm{x}$ & $\mathrm{x}$ \\
\hline Pontoações intervasculares alternas & $\mathrm{x}$ & $\mathrm{x}$ & $\mathrm{x}$ & $\mathrm{x}$ & $\mathrm{x}$ \\
\hline Presença de traqueídeos vasculares & $\mathrm{x}$ & $\mathrm{x}$ & & & \\
\hline Parênquima paratraqueal seriado & $\mathrm{x}$ & $\mathrm{x}$ & $\mathrm{x}$ & $\mathrm{x}$ & $\mathrm{x}$ \\
\hline Parênquima apotraqueal seriado & & & & & $\mathrm{x}$ \\
\hline Séries com até 4 células & $\mathrm{x}$ & & $\mathrm{x}$ & & \\
\hline Séries com até 6 células & & $\mathrm{x}$ & & & \\
\hline Séries com até 8 células & & & & $\mathrm{x}$ & $\mathrm{x}$ \\
\hline Raios heterogêneos não estratificados & $\mathrm{x}$ & $\mathrm{x}$ & $\mathrm{x}$ & $\mathrm{x}$ & $\mathrm{x}$ \\
\hline Raios com até 3 células de largura & & & $\mathrm{x}$ & & \\
\hline Raios com até 4 células de largura & & $\mathrm{x}$ & & & \\
\hline Raios com mais de 4 células & $\mathrm{x}$ & & & $\mathrm{x}$ & $\mathrm{x}$ \\
\hline Presença de cristais & $\mathrm{x}$ & & & $\mathrm{x}$ & $\mathrm{x}$ \\
\hline Presença de células perfuradas & $\mathrm{x}$ & & $\mathrm{x}$ & & \\
\hline Fibras libriformes & $\mathrm{x}$ & $\mathrm{x}$ & $\mathrm{x}$ & $\mathrm{x}$ & $\mathrm{x}$ \\
\hline Fibras de paredes espessas & $\mathrm{x}$ & $\mathrm{x}$ & $\mathrm{x}$ & & $\mathrm{x}$ \\
\hline Fibras de paredes delgadas & & & & $\mathrm{x}$ & \\
\hline$\varnothing$ de poros $(\mu \mathrm{m})$ & 28 & 31 & 161 & 46 & 50 \\
\hline Fração de poros $(\%)$ & 17 & 16 & 39 & 12 & 16 \\
\hline Freqüência de poros $\left(\mathrm{mm}^{2}\right)$ & 335 & 485 & 62 & 109 & 82 \\
\hline Comprimento de vasos & 264 & 273 & 187 & 389 & 298 \\
\hline$\varnothing$ pontoações intervasculares & 6 & 6,5 & 9,3 & 7,9 & 3,6 \\
\hline Altura séries parênquima axial $(\mu \mathrm{m})$ & 225 & 244 & 243 & 389 & 266 \\
\hline Fração de raios (\%) & 28 & 14 & 14 & 12 & 32 \\
\hline Freqüência linear de raios $(\mathrm{mm})$ & 17 & 13 & 13 & 9 & 21 \\
\hline Altura máxima de raios multisseriados (células) & 56 & 36 & 89 & 50 & 59 \\
\hline Altura máxima de raios unisseriados (células) & 17 & 18 & 18 & 19 & 33 \\
\hline Altura de raios multisseriados $(\mu \mathrm{m})$ & 473 & 405 & 497 & 336 & 569 \\
\hline Altura de raios unisseriados $(\mu \mathrm{m})$ & 192 & 186 & 205 & 116 & 239 \\
\hline Fração de parênquima axial (\%) & 5 & 8 & 9 & 5 & 14 \\
\hline Comprimento máximo de fibras & 1180 & 810 & 1240 & 860 & 1110 \\
\hline Fração de fibras (\%) & 51 & 62 & 37 & 71 & 38 \\
\hline
\end{tabular}

Os valores expressos na tabela são médios, exceto quando especificado; $C$. p. = Colletia paradoxa; $D$. a. $=$ Discaria americana; G. u. = Gouania ulmifolia; $R . s .=$ Rhamnus sphaerosperma; $S . b .=$ Scutia buxifolia $; \varnothing=$ diâmetro; $\mu \mathrm{m}=$ micrômetro. 
Hess (1949) e Metcalfe \& Chalk (1972) para as Rhamnaceae, com exceção da presença de apêndices em elementos vasculares, aspecto não citado pelos mesmos autores.

Apesar de compartilharem muitas características, as cinco espécies apresentam particularidades anatômicas suficientes para a identificação, salientando-se: o volume ocupado pelos diferentes tecidos na madeira; o arranjo de poros; o dimorfismo e presença de espessamentos espiralados em vasos; o diâmetro de pontoações intervasculares; a presença de traqueídeos; o tipo e altura das séries de parênquima axial; a composição, largura e altura de raios, bem como a presença de cristais e células perfuradas neste tecido; além do comprimento e espessura da parede de fibras. Um resumo das principais características anatômicas qualitativas e quantitativas é apresentado na Tabela 1, para as cinco espécies.

Com madeiras estruturalmente semelhantes, Discaria americana e Colletia paradoxa distinguem-se pelos poros organizados em padrão nitidamente diagonal a dendrítico (Figura 1A), bem como pela presença de traqueídeos vasculares. $D$. americana separa-se de $C$. paradoxa, por sua vez, pela presença de séries parenquimáticas mais altas, geralmente com 4 (6) células, além de raios mais estreitos e baixos, com 1-4 células de largura e 6-36 células de altura (Figura 1I). Em C. paradoxa, as séries de parênquima axial reúnem geralmente 2 (4) células e os raios, com 1-7 células de largura e 7-56 células de altura, apresentam células perfuradas. Além disso, o tecido radial é mais abundante nesta espécie (superior a $20 \%$ do total dos tecidos) e as fibras são mais longas, com comprimento máximo em torno de $1200 \mu \mathrm{m} ; D$. americana, em contraste, apresenta raios mais escassos (não ultrapassando $20 \%$ do volume da madeira) e fibras menores, com comprimento máximo de apenas $800 \mu \mathrm{m}$.

Independentemente do sistema de classificação vegetal e das características utilizadas, os gêneros Discaria e Colletia sempre foram posicionados no mesmo grupo (tribo Colletieae). A grande afinidade observada entre a estrutura anatômica de Discaria americana e Colletia paradoxa confirma tal interpretação, concordando, neste aspecto, com os resultados da análise morfológica e molecular (Richardson et al., 2000). Embora possam ser separadas pela anatomia, as diferenças entre Colletia e Discaria são pouco significativas, sendo, inclusive, menores do que o observado em alguns subgêneros da família, como no caso de Frangula e Eurhamnus, integrantes do gênero Rhamnus.

Única espécie com hábito de liana, Gouania ulmifolia separa-se prontamente das demais espécies pelo grande diâmetro e elevada freqüência de poros (superior a 30\% do volume da madeira), bem como pelo dimorfismo de vasos, pela ausência de espessamentos espiralados, pelos elementos vasculares mais curtos e com perfurações frequientemente transversais, pelas pontoações intervasculares com abertura em fenda, e pelos raios multisseriados mais estreitos e altos (1-3 células de largura e 9-89 células de altura), com abundantes células perfuradas. Este último aspecto, aliás, foi também observado em Colletia paradoxa, como anteriormente mencionado (Figura 1H,L). Parte destas características pode ser atribuída ao hábito trepador: é o caso da presença de elementos de vasos curtos e de grande diâmetro; das placas transversais; do dimorfismo de vasos; e da baixa percentagem de fibras (Peñalosa, 1985; Carlquist, 1991).

Com relação a Rhamnus sphaerosperma, a madeira distingue-se pelos poros poligonais, solitários e em múltiplos radiais e racemiformes, pelos elementos vasculares mais longos, pelas séries de parênquima axial com 2-8 células, pelos raios mais escassos, de 1-5 células de largura e com apenas células procumbentes na parte multisseriada, além das fibras extremamente curtas a muito curtas, de paredes delgadas (Figura 1D.E). A estrutura anatômica coincide com o relacionado para o subgênero Frangula, por Record \& Hess, (1949), concordando, neste 


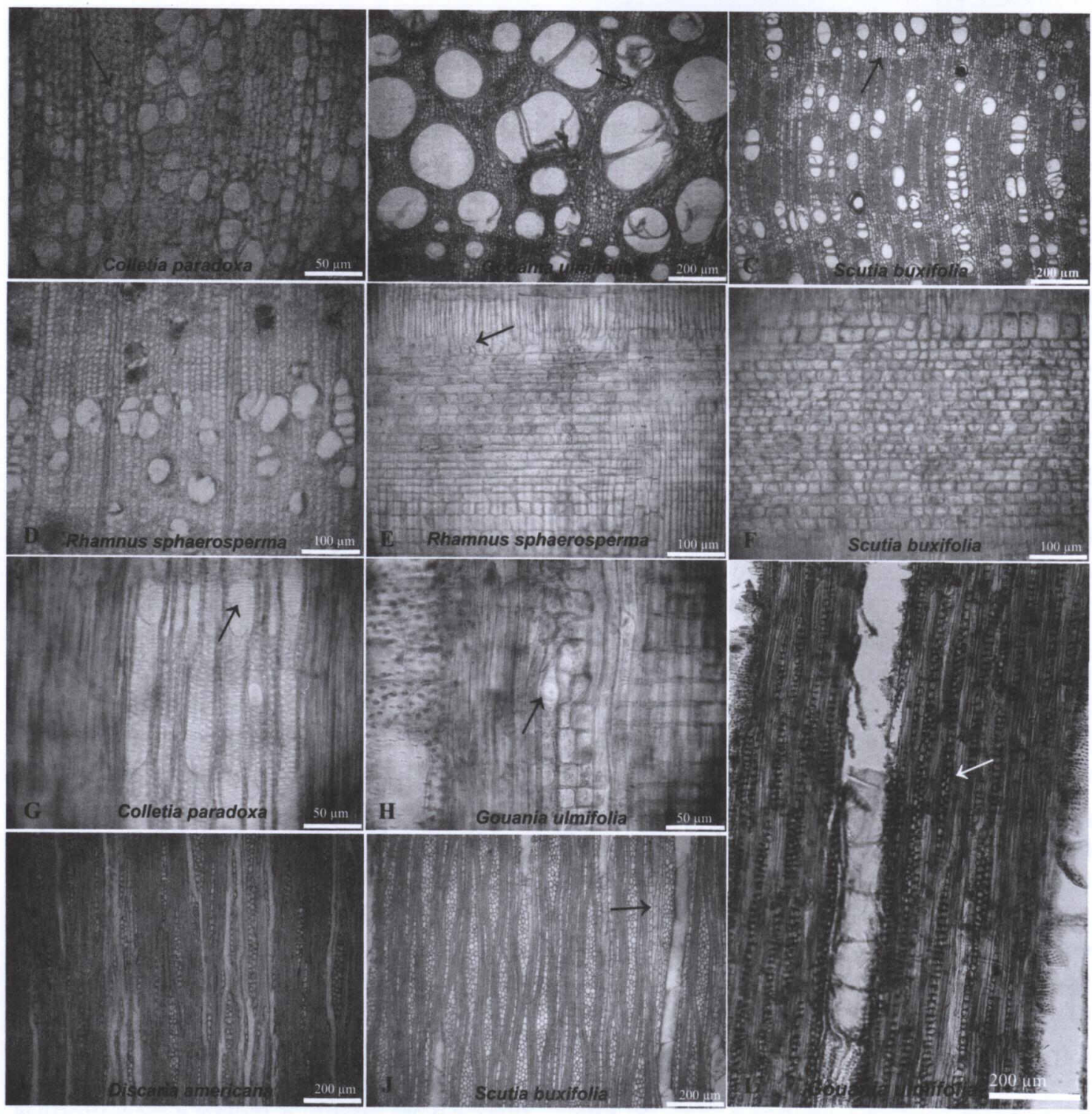

FIGURA 1 - Aspectos anatômicos em madeiras de Rhamnaceae. A-D - Cortes em seção transversal. A - Poros em arranjo dendrítico, com parênquima paratraqueal escasso (seta). B - Porosidade em anel e dimorfismo de vasos (seta). C - Poros solitários e em múltiplos radiais, com parênquima apotraqueal marginal (seta). D - Poros solitários e em múltiplos radiais, com fibras de paredes finas. E-H - Cortes em seção longitudinal radial. E - Raio heterogêneo, com corpo de células procumbentes e cristais escassos (seta). F - Raio heterogêneo, com corpo de células procumbentes, quadradas e abundantes cristais. G - Vasos com placas de perfuração simples e espessamentos espiralados (seta). H - Célula perfurada de raio (seta). I-L - Cortes em seção longitudinal tangencial. I - Raios com até 4 células de largura. J - Raios com mais de 4 células de largura e parênquima axial seriado (seta). L - Vasos de grande diâmetro e raios altos, com 1-3 células de largura (seta). 
aspecto, com a interpretação de Johnston \& Johnston (1978), feita com base na morfologia externa.

Scutia buxifolia pode ser identificada pela presença de poros solitários e em múltiplos radiais, de contorno oval e com abundante conteúdo no cerne, pelas pontoações intervasculares pequenas $(<4 \mu \mathrm{m})$, notavelmente menores do que nas demais espécies, pela presença de parênquima apotraqueal marginal, em séries com 3-8 células, pelos raios com 1-6 células de largura, mas com unisseriados predominantes e abundantes cristais (Figura 1C,F,J). Convém lembrar que os raios de $C$. paradoxa e $S$. buxifolia possuem a mesma largura; as duas espécies, todavia, são facilmente separadas pela classe predominante: mais de quatro células $(42 \%) \mathrm{e}$ unisseriados $(28 \%)$, respectivamente. Da mesma forma, as séries de parênquima axial em $S$. buxifolia atingem a mesma altura em células, observada em Rhamnus sphaerosperma; o comprimento linear $(\mu \mathrm{m})$, todavia, é consideravelmente inferior, servindo para a separação de ambas.

A freqüência, diâmetro e comprimento de elementos vasculares, bem como a porosidade, mostram-se variáveis nas cinco espécies estudadas (Tabela 1). Tais características, todavia, estão mais sujeitas à variação por fatores ambientais ou hábito de crescimento, conforme demonstrado em inúmeros trabalhos de anatomia ecológica (Carlquist, 1966; Baas, 1973; Carlquist, 1975; Baas et al., 1983; BarajasMorales, 1985; Carlquist \& Hoekman, 1985; Roig, 1986; Baas \& Schweingruber, 1987; Lindorf, 1994; León, 2005).

As cinco espécies em estudo podem ser anatomicamente separadas pela seguinte chave dicotômica:

1a. Elementos vasculares com espessamentos espiralados; fração de poros inferior a $30 \%$ do volume da madeira.

2a. Poros em arranjo diagonal a dendrítico.

3a. Séries parenquimáticas geralmente com 2 células; fração de raios superior a

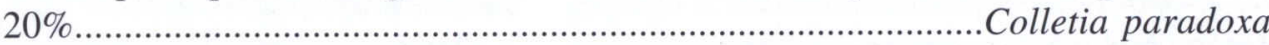

3b. Séries parenquimáticas geralmente com 4 células; fração de raios inferior a

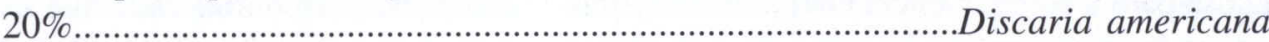

2b. Poros solitários e em múltiplos radiais.

4a. Presença de parênquima apotraqueal marginal, raios com células procumbentes, quadradas e eretas na parte multisseriada................Scutia buxifolia

4b. Parênquima apotraqueal ausente, apenas células procumbentes na parte multisseriada dos raios...............................................Rhamnus sphaerosperma

1b. Elementos vasculares sem espessamentos espiralados; fração de poros superior a 30\% do volume da madeira Gouania ulmifolia

\section{CONSIDERAÇÕES ECOLÓGICAS E EVOLUTIVAS}

Com exceção de Gouania ulmifolia, espécie com hábito de liana, verifica-se um nítido predomínio de caracteres xeromórficos no material em estudo, incluindo elementos vasculares curtos, com placas de perfuração simples e espessamentos espiralados na parede, bem como poros numerosos e estreitos, agrupados em múltiplos.

Em ambientes secos, a ocorrência de embolismos nas colunas d'água e o colapso de vasos, decorrentes de pressões negativas muito altas no xilema, são as causas mais importantes 
para a interrupção do fluxo de seiva (Lindorf, 1994). Em contraposição, as espécies podem desenvolver variadas adaptações na arquitetura anatômica, como as citadas anteriormente, visando superar os referidos problemas.

Segundo Carlquist (1975), a vantagem estrutural oferecida por elementos de vaso curtos e estreitos reside no fortalecimento mecânico dos mesmos, permitindo seu funcionamento, sem colapso, sob elevadas tensões nas colunas d'água. Além de resistirem melhor ao colapso, elementos de vaso estreitos aumentam a segurança condutiva por proporcionarem maior adesão da água junto à parede, reduzindo a ocorrência de cavitações. Por outro lado, vasos estreitos oferecem maior fricção ao fluxo, aspecto não desvantajoso se a velocidade de condução da seiva é lenta, como verificado em espécies xeromórficas. $\mathrm{O}$ encurtamento de elementos vasculares, por sua vez, pode também refletir um grau evolutivo mais elevado do grupo taxonômico; como discutido posteriormente, todavia, tais tendências podem ser eventualmente revertidas por especialização adaptativa às condições ambientais.

A presença de vasos numerosos e agrupados em múltiplos mostra-se especialmente vantajosa para a sobrevivência em plantas sujeitas a elevadas pressões negativas, por garantir maior eficiência e segurança na condução, proporcionando vias alternativas ao fluxo da água, caso ocorram embolismos (Baas et al., 1983; León, 2005). Conforme Zimmermann (1982), vasos largos são eficientes à condução, embora vulneráveis, ao passo que os estreitos são mais seguros, desde que em maior número.

A elevada percentagem de arbustos xéricos com espessamentos espiralados nos vasos indica que o caráter tem valor adaptativo em regiões secas, seja pelo aumento da resistência ao colapso, resultante do fortalecimento da parede dos vasos (Webber, 1936; Carlquist, 1975), seja pelo aumento da superfície de contato dos mesmos com a coluna d'água (Carlquist, 1982). Tais interpretações, todavia, não esclarecem comple- tamente a questão, segundo Baas et al. (1983) e Baas \& Schweingruber (1987), de modo que a presença dessas estruturas permanece indefinida em termos de função. Por outro lado, é de consenso entre os pesquisadores que a ocorrência de espessamentos espiralados aumenta com a latitude, tendência observada, inclusive, na flora brasileira (Alves \& Angyalossy-Alfonso, 2000). A presença de espessamentos espiralados em quatro das cinco espécies estudadas contribui favoravelmente a esta interpretação, sobretudo se levado em conta que o Rio Grande do Sul é o estado mais austral do Brasil.

Perfuração simples é o tipo mais comum de placa. Para a flora brasileira, Alves \& Angyalossy-Alfonso (2000), reportam o caráter para 95\% das espécies nativas, vinculando o mesmo a ambientes secos e quentes, com elevada taxa de transpiração. De acordo com Carlquist (1975), perfurações simples são mais eficientes para a condução de grandes volumes de água por unidade de tempo, pois oferecem menor resistência ao fluxo. Tal opinião é compartilhada por Wheeler \& Baas (1991), que consideram perfurações simples mais eficientes no caso de intenso fluxo hídrico.

Tendo em vista o clima nitidamente ombrófilo e com boa disponibilidade hídrica, atualmente vigente no Rio Grande do Sul (Buriol et al., 2007), a ocorrência eventual de estiagens, mesmo agravada por certas características edáficas (solos rasos, arenosos, presença de pedras e relevo acentuado), não permite vincular, em princípio, o conjunto de características anatômicas observado às condições ambientais. Como sugerido por Baas \& Schweingruber (1987), tais tendências podem resultar de eventos de especialização no passado, que, não sendo desvantajosas, lograram persistir na estrutura anatômica das espécies. Por outro lado, não se pode descartar a possibilidade de que, em certos casos, a presença de tais aspectos anatômicos represente vantagens adaptativas. Considerando a ocorrência destes caracteres especializados em vários gêneros da família, é possível presumir, também, 
que alguns aspectos da morfologia dos vasos estejam mais relacionados ao grupo taxonômico do que, propriamente, a condições ambientais, notadamente o tamanho de pontoações, natureza das placas de perfuração e comprimento de elementos vasculares (Baas et al., 1983; León, 2005).

Certos aspectos da estrutura anatômica podem ser influenciados pelo hábito de crescimento das plantas. No material analisado, a freqüência e diâmetro de poros variam de modo inverso (Tabela 1): a freqüência de poros aumenta de lianas (Gouania ulmifolia) para árvores (Scutia buxifolia e Rhamnus sphaerosperma) e arbustos (Discaria americana e Colletia paradoxa), ao passo que o diâmetro dos vasos diminui na mesma direção. Tais tendências concordam com os resultados de Marchiori (1990), que observou uma relação inversa entre diâmetro e frequiência de poros em espécies com formas de crescimento e ecologia distintas, com exceção do hábito de liana. De acordo com o mesmo autor, a freqüência de poros é maior em lianas do que em arbustos, contrariando os resultados obtidos neste estudo. Vasos de grande diâmetro são típicos da estrutura anatômica de lianas e possuem valor adaptativo, segundo a interpretação de vários autores (Carlquist, 1985; Araque et al., 2007).

Verificou-se, ainda, uma tendência de aumento no comprimento médio de elementos vasculares, do hábito de liana para o arbustivo e arbóreo, concordando com os resultados de Baas et al. (1983), que comprovaram elementos vasculares mais longos em árvores do que em arbustos (Tabela 1). Segundo Carlquist (1975), o comprimento de elementos vasculares em lianas e trepadeiras é geralmente inferior ao dobro de sua largura: ocorre que a redução no comprimento de vasos largos, de acordo com o mesmo autor, favorece a resistência ao colapso, decorrente de altas pressões negativas.

Com relação à evolução, placas de perfuração simples, pontoações intervasculares alternas, elementos vasculares curtos, parênquima paratraqueal e fibras libriformes, características comuns às cinco espécies em estudo, bem como às Rhamnaceae como um todo, são indicativas de especialização ou alto grau evolutivo no xilema secundário (Bailey, 1953; Metcalfe \& Chalk, 1972; Dickison, 1975; Wheeler \& Baas, 1991). Por outro lado, de acordo com os critérios de Kribs (1935) e Barghoorn (1941), a presença de raios heterogêneos sugere primitividade, aspecto, todavia, de menor importância, face aos demais . Vale lembrar, ainda, que grupos altamente especializados podem apresentar características anatômicas primitivas: é o caso, por exemplo, do gênero Heterothalamus (Asteraceae), cujas espécies são providas de raios heterogêneos (Oliveira et al., 2005).

Em Discaria americana e Colletia paradoxa foram observados traqueídeos vasculares, característica igualmente interpretada como primitiva (Burger \& Richter, 1991). Resta considerar que a retenção de elementos imperfurados, bem como a ocorrência de elementos vasculares curtos, nem sempre devem ser consideradas como parâmetros para avaliação do grau evolutivo, uma vez que sua presença pode decorrer de adaptação das espécies ao ambiente, como anteriormente discutido. Baas (1973) e Carlquist (1975) explicam que fatores ecológicos e fisiológicos podem, eventualmente, reverter tendências de especialização filogenética em características anatômicas, motivo pelo qual nem sempre as espécies mais evoluídas são as que apresentam elementos vasculares mais curtos.

\section{REFERÊNCIAS BIBLIOGRÁFICAS}

ALVES, E. S., ANGYALOSSY-ALFONSO, V. Ecological trends in the wood anatomy of some brazilian species: growth rings and vessels. IAWA Bulletin, v. 21, p. 3-30, 2000.

ARAQUE, O., LEÓN, W., HERNÁNDEZ, C. Anatomia xilemática de lianas de la familia Bignoniaceae en la reserva forestal de Caparo (Barinas, Venezuela). Acta Botánica Venezuelica, v. 30, n. 1, p. 191-215, 2007. 
BAAS, P. The wood anatomical range in Ilex (Aquifoliaceae) and its ecological and phylogenetic significance. Blumea, v. 21, n. 2, p. 193-258, 1973.

BAAS, P. Systematic, phylogenetic and ecological wood anatomy - History and perspectives. In: BAAS, P. (ed): New perspectives in wood anatomy. The Hague: Martinus Nijhoff Publishers, 1982. p. 23-58.

BAAS, P., WERKER, E., FAHN, A. Some ecological trends in vessel characters. IAWA Bulletin, v. 4, p. 141-160, 1983.

BAAS, P., SCHWEINGRUBER, F. H. Ecological trends in wood anatomy of trees, shrubs and climbers from Europe. IAWA Bulletin, v. 8, p. 245-274, 1987.

BASTOS, N. R. A familia Rhamnaceae R. Br. no RS: gêneros Condalia Cav. e Scutia Comm. Pesquisas-Botânica, São Leopoldo, n. 40, p. 69-84, 1989.

BASTOS, N. R. A familia Rhamnaceae R. Br. no RS: gêneros Colubrina Rich. ex. Brongn., Gouania Jacq. e Hovenia Thunb. Peśquisas-Botânica, São Leopoldo, n. 41, p. 99-122, 1990.

BASTOS, N. R. A familia Rhamnaceae R. Br. no RS: gênero Rhamnus L. Pesquisas-Botânica, São Leopoldo, n. 44, p. 83-94, 1993.

BARAJAS-MORALES, J. Wood structural differences between trees of two tropical forests in Mexico. IAWA Bulletin, v. 6, n. 4, p. 355-364, 1985.

BARGHOORN, JR., E. S. The ontogenetic development and phylogenetic specialization of rays in the xylem of Dicotyledons. II. Modification of the multisseriate and unisseriate rays. American Journal of Botany, n. 28, p. 273-282, 1941.

BAILEY, I. W. Evolution of the tracheary tissue of land plants. American Journal of Botany, n. 40, p. 4-8, 1953.

BURGER, L. M., RICHTER, H. G. Anatomia da Madeira. São Paulo: Ed. Nobel, 1991. 154p.

BURIOL, G. A., ESTEFANEL, V., CHAGAS, A. C., EBERHARDT, D. Clima e vegetação natural no estado do Rio Grande do Sul segundo o diagrama climático de Walter e Lieth. Ciência Florestal, v. 17, n. 2, p. 91-100, 2007.

CARLQUIST, S. Wood anatomy of Compositae: a summary with comments on factors controlling wood evolution. Aliso, v. 6, n. 2, p.25-44, 1966.

CARLQUIST, S. Ecological strategies of xylem evolution. Berkeley: University of California Press, 1975.259p.
CARLQUIST, S. Wood anatomy of Illicium (Illiciaceae): phylogenetic, ecological and functional interpretations. American Journal of Botany, v. 69, p. 1587-1598, 1982.

CARLQUIST, S. Observations on wood functional histology of vines and lianas: vessel dimorphism, tracheids, vasicentric tracheids, narrow vessels and parenchyma. Aliso, v. 11, n. 2, p. 139-157, 1985.

CARLQUIST, S., HOEKMAN, D. A. Ecological wood anatomy of the woody southern Californian flora. IAWA Bulletin, v. 6, n. 4, p. 319-347, 1985.

CARLQUIST, S. Anatomy of vine and liana stems: a review and synthesis. In: PUTZ, F. E., MOONEY, H. A. The Biology of Vines. Cambridge: Cambridge University Press, 1991. p. 53-72.

DICKISON, W. C. The basis of Angiosperm Phylogeny: Vegetative anatomy. Annals of Missouri Botanic Garden, v. 62, p. 596-620, 1975.

HERENDEEN, P. S., WHEELER, E. A., BAAS, P. Angiosperm wood evolution and the potential contribution of paleontological data. The Botanical Review, v. 65, n. 3, p. 278-300, 1999.

JOHNSTON, M. C., SOARES, M. A. F. Ramnáceas. In: Reitz, R. Flora Ilustrada Catarinense. Itajaí: Herbário Barbosa Rodrigues, 1972. 50p.

JOHNSTON, M. C., JOHNSTON, L. V. A. Rhamnus. Flora Neotropica, n. 20, p.1-96, 1978.

KRIBS, D. A. Salient lines of structural specialization in the wood rays of Dicotyledons. Botanical Gazette, v. 96, p. 547-557, 1935.

LEÓN, W. Anatomía ecológica del xilema secundario de un bosque seco tropical de Venezuela. Acta Botánica Venezuelica, v. 28, n. 2, p. 1-22, 2005.

LINDORF, H. Eco-anatomical wood features of species from a very dry tropical forest. IAWA Bulletin, v. 15, p. 361-376, 1994.

MARCATI, C. R., ANGYALOSSY-ALFONSO, V., BENETATI, L. Anatomia comparada do lenho de Copaifera langsdorffii Desf. (Leguminosae Caesalpinoideae) de floresta e cerradão. Revista Brasileira de Botânica, v. 24, n. 3, p. 311-320, 2001.

MARCHIORI, J. N. C. Anatomia da madeira de Colletia paradoxa (Spreng.) Escalante. Ciência e Natura, Santa Maria, n. 5, p. 161-170, 1983.

MARCHIORI, J. N. C. Anatomia das madeiras do gênero Acacia, nativas e cultivadas no Estado do Rio Grande do Sul. 1990. 226f. Tese (Doutorado em Engenharia Florestal) - Universidade Federal do Paraná, Curitiba, 1990. 
MARCHIORI, J. N. C., OLIVEIRA-DEBLE, A. S.Anatomia da madeira da subtribo Baccharinae Less.: tendências gerais de ordem taxonômica e ecológica. Balduinia, Santa Maria, n. 11, p. 9-15, 2007.

METCALFE, C. R., CHALK, L. Anatomy of the Dicotyledons. Oxford: Clarendon Press, 1972. $1500 \mathrm{p}$.

OLIVEIRA, A. S., DEBLE, L. P., MARCHIORI, J. N.C. Anatomia da madeira de duas espécies do gênero Heterothalamus Lessing (Asteraceae), nativas no Rio Grande do Sul. Ciência Florestal, Santa Maria, v. 15, n. 1, p. 9-19, 2005.

PEÑALOSA, J. Dinámica de crescimento de lianas. In: GOMES-POMPA, A., DEL AMO, R. S. Investigaciones sobre la regeneración de selvas altas em Vera Cruz, México. México: Alhambra Mexicana, 1985. v. 2.p. 147-169.

RADFORD, A. E., DICKSON, W. C., MASSEY, J. R., BELL, C. R. Vascular Plant Systematics. New York: Harper \& Row, 1974. 891p.

RECORD, S. J. American woods of the family Rhamnaceae. Tropical Woods, n. 58, p. 6-24, 1939.

RECORD, S. J., HESS R. W. Timbers of the New World. New Haven: Yale University Press, 1949.640p.

RICHARDSON, J. E., FAY, M. F., CRONK, Q. C. B., BOWMAN, D., CHASE, M. W. A phylogenetic analysis of Rhamnaceae using $r b c L$ and $t r n-F$ plastid DNA sequences. American Journal of Botany, v. 87, n. 9, p. 1309-1324, 2000.

ROIG, F. The wood of Adesmia horrida and its modifications by climatic conditions. IAWA Bulletin, v. 7, n. 2, 1986.

SANTOS, S. R., MARCHIORI, J. N. C., CANTODOROW, T. S. Anatomia da madeira e descrição morfológica de Scutia buxifolia Reissek (Rhamnaceae). Balduinia, Santa Maria, n. 14, p. 19-28, 2008.
SANTOS, S. R., MARCHIORI, J. N. C., CANTODOROW, T. S. Estudo anatômico do lenho e descrição morfológica de Gouania ulmifolia Hooker et Arnott (Rhamnaceae). Balduinia, Santa Maria, n. 13, p. 15-26, 2008.

SANTOS, S. R., MARCHIORI, J. N. C., CANTODOROW, T. S. Estudo anatômico do lenho e descrição botânica de Rhamnus sphaerosperma Swartz (Rhamnaceae). Balduinia, Santa Maria, n. 11, p. 16-26, 2007.

SANTOS, S. R., MARCHIORI, J. N. C., CANTODOROW, T. S. Identificação botânica e anatomia da madeira de Discaria americana Gillies et Hooker. Balduinia, Santa Maria, n. 10, p. 11-20, 2007.

SCHIRAREND, C. The systematic wood anatomy of the Rhamnaceae Juss. (Rhamnales) - Tribe Zizipheae. IAWA Bulletin, v.12, n. 4, p. 359-388, 1991.

SOUZA, V. C., LORENZI, H. Botânica Sistemática: guia ilustrado para identificação das famílias de Angiospermas da flora brasileira, baseado em APG II. Nova Odessa: Instituto Plantarum, 2005. $640 \mathrm{p}$.

WEBBER, I. E., The woods of sclerophyllous and desert shrubs and desert plants of California. American Journal of Botany, v. 23, p. 181-188, 1936.

WHEELER, E. A., BAAS, P. A survey of the fossil record for Dicotyledonous wood and its significance for evolutionary and ecological wood antomy. IAWA Bulletin, v. 12, n. 3, p. 275 332, 1991.

ZIMMERMANN, M. H. Functional xylem anatomy of Angiosperm trees. In: BAAS, P. New perspectives in wood anatomy. The Hague: Nijhoff/Junk, 1982. p. 59-70. 